\section{Inserção social e habitação de pessoas com so- frimento mental grave. Juarez Pereira Furtado e Eunice Nakamura (orgs.). São Paulo: Editora FAP-Unifesp, 2014. 432 p.}

\author{
Nina Soalheiro \\ Escola Politécnica de Saúde Joaquim Venâncio, Fundação \\ Oswaldo Cruz, Rio de Janeiro, Brasil \\ $<$ ninasoalheiro@fiocruz.br>
}

http://dx.doi.org/10.1590/1981-7746-sip00129

O livro Inserção social e habitação de pessoas com sofrimento mental grave demanda fôlego do seu leitor, o mesmo que foi necessário aos organizadores e autores para nos apresentar os resultados de um trabalho assumidamente longo e complexo. Organizado por um profissional da saúde coletiva com larga experiência no campo da saúde mental e uma antropóloga que tem seus estudos também voltados para o campo, o livro reúne pesquisadores de diferentes áreas de conhecimento, mas orientados por uma metodologia rigorosamente interdisciplinar. Por isso não é uma leitura fácil nem dada a simplismos; ao contrário, vai muito além dos limites conceituais já consagrados no campo da atenção psicossocial.

Desde o título, o livro deixa claro que os organizadores e autores falam de inserção social e não de 'reinserção social' ou 'reabilitação psicossocial'; falam de habitação e não apenas de 'residências terapêuticas' ou 'serviços residenciais terapêuticos'; falam de pessoas com sofrimento mental e não de 'portadores de transtornos mentais' ou 'pacientes psiquiátricos'. E demonstram que não são dados a caminhos fáceis, já que escolhem falar de pessoas com sofrimentos graves. Isso já nos dá uma boa medida da obra, a qual apresenta uma pesquisa inovadora no campo da saúde mental e atenção psicossocial, esta tão carente de sistematizações de fôlego, seja pela complexidade de fazê-lo, seja por nos contentarmos apenas com aquilo que nos cabe fazer.

A pesquisa que deu origem ao livro é resultado de indagações teóricas e políticas da equipe, a partir dos novos desafios trazidos pelo conjunto de mudanças implementadas pela Reforma Psiquiátrica Brasileira, particularmente na área de suporte social a moradias e habitação de pacientes com sofrimento mental grave. Dentro desse contexto de consolidação de uma saúde mental pós asilar, o livro ressalta a diferença fundamental entre morar e habitar: morar refere-se ao espaço, conforto e proteção que constituem a residência; habitar, ao modo de apropriação da moradia, inclui a história e o estilo de ser daquele que vive nela.

O campo da pesquisa é constituído por três municípios diferentes, duas capitais estaduais e um município contíguo a uma região metropolitana, os quais foram definidos por terem uma rede de saúde mental diversificada e já consolidada. A equipe de pesquisadores foi composta a partir da característica qualitativa, interdisciplinar e participativa do estudo, reunindo pesquisadores de quatro importantes áreas de conhecimento para abordagem do tema: antropologia, arquitetura, saúde coletiva e psicanálise. Uma perspectiva interdisciplinar sem pretensões holísticas, apenas baseada num roteiro comum e no compartilhamento exaustivo da experiência com o 'objeto' e campo. 
Dessa forma, os resultados apresentam um conjunto de análises muito ricas, organizadas tanto por categorias específicas a cada uma das áreas de conhecimento quanto por um esforço de síntese e reconstrução do objeto através dos diferentes olhares. O livro e seu conjunto de capítulos materializam aquilo que insistentemente temos afirmado sobre a natureza interdisciplinar e intersetorial da atenção psicossocial e a necessidade intrínseca ao campo de agregar múltiplos saberes e abordagens. Para isso os organizadores estruturam o trabalho em três partes que reconstituem o longo caminho percorrido pela equipe da pesquisa.

A primeira parte, intitulada "Morar, habitar, inserir: perspectivas da arquitetura, antropologia, psicanálise e saúde coletiva", representa um esforço de sistematização e compartilhamento com o leitor dos aspectos teóricos e conceituais de cada uma das áreas de conhecimento. Sem se ater a um mero exercício epistemológico acadêmico, o texto é radicalmente focado no objeto e no compromisso social da pesquisa.

A partir dos autores arquitetos vem a compreensão da casa como lugar de proteção das intempéries e a poética da nossa eterna relação com ela, sempre em construção. Apresentam-na em suas múltiplas dimensões de fundação, abrigo e construção material de nossa presença no mundo. E, sobretudo, relatos que trazem um olhar profundamente crítico das distorções presentes nos serviços estudados, detalhes que muitas vezes não conseguimos enxergar.

Os autores antropólogos trazem uma contribuição importante para o nosso campo, na medida que desvelam a insuficiência das definições simplistas de inserção social e ressaltam o valor de uma perspectiva etnográfica 'de dentro', aquela que analisa o pertencimento das moradias ao conjunto da organização social e cultural que produz exclusão.

Os autores da saúde coletiva não poupam esforços para situar o leitor na historicidade das políticas públicas para a área no Brasil, incluindo também um breve painel de experiências nacionais e internacionais relevantes. Discutem políticas e projetos de suporte social a moradias e habitação, sem abrir mão da dimensão simbólica envolvida nessa construção, sempre presente no livro como um todo. O que é muito bem ilustrado com a referência ao caso de um senhor que, chegando num Serviço Residencial Terapêutico no qual finalmente consegue uma vaga, deposita sua sacola sobre a cama e surpreende com a frase: "Agora posso viajar!". Os espaços públicos de moradia têm que comportar pertencimento e errâncias, ser porto seguro para andanças que agora incluem o voltar.

Por fim, os autores psicanalistas ressaltam a importância da articulação entre singular e universal para a construção do habitar. Apostam na natureza essencialmente simbólica desta construção, única para cada sujeito, sem projeto comum para todos. A nós restaria apenas acompanhar os modos de habitar o mundo e o campo do Outro onde os sujeitos podem encontrar sua casa.

A segunda parte do livro é intitulada "Processos de investigação", formada por sete capítulos que, segundo os organizadores, traduziria o 'como fizemos'. Inclui reflexões teóricas sobre os diferentes métodos e técnicas de pesquisa utilizados e, mais importante, a narrativa dos pesquisadores sobre a experiência de campo. Um 'campo' na verdade constituído pela equipe em interação com os diferentes territórios de vida dos sujeitos pesquisados, trazendo experiências de imersão etnográfica e biográficas. Aqui encontramos uma pesquisa essencialmente qualitativa, levando a termo aquilo que é a potência desse modo de investigação: dar consistência a mundos obscuros e invisíveis, os quais só são acessíveis com extrema aproximação de rotinas e de vidas.

Em cada um dos capítulos encontramos pesquisadores sem medo do seu próprio estranhamento de mundos caóticos e sem pudor de nos fazer participar dos seus diálogos internos, mas sem deixar de sempre retornar ao seu papel de análise e reflexão dessas experiências. Um trabalho essencialmente etnográfico, na medida em que há uma imersão no campo de estudo, sistematizando experiências de compartilhamento com os sujeitos em seu espaço de vida e utilizando técnicas voltadas para uma descrição densa e profunda do universo sócio/cultural.

Destaca-se aqui o texto "Entre corredores e labirintos: a narrativa como fio de Ariadne", uma referência mitológica ao desafio de adentrar labirintos da vida e conseguir sair. E os labirintos aqui incluem não só os espaços protegidos dos serviços, as instituições estudadas, mas também os becos, ruelas e os lados escuros e obscuros da cidade. Dessa forma, o trabalho dos pesquisadores prossegue ancorado num desenho de pes- 
quisa suficientemente ousado para investigar com rigor metodológico 'a vida como ela é', desnudando poderes, abusos e solidariedades no mundo de pessoas que aprendem a viver com um olho aberto e outro fechado.

São descrições de personagens reais que apresentam modos singulares de habitação, que falam sobre uma relação complexa entre a vida íntima e a ordem esperada aos espaços públicos, que demonstram como os modos de habitar tem a ver com as histórias e marcas de cada um. O habitar é uma construção que conecta mundo interno e universo social e cultural, produzindo infinitos modos de viver a vida. Há o Rivaldo que vive numa casa inacabada, há o Anastácio que ainda não encontrou sua casa, mas construiu formas próprias de se proteger, há a Armênia, uma hóspede itinerante da cidade...

Encontramos também uma reflexão mais voltada para a sistematização dos desafios apresentados por uma política suficientemente construída para que possa ser avaliada, mas ainda em construção, de forma a comportar uma ação reflexiva sobre posturas e práticas, e incorporar novos saberes. Nesse ponto é importante a característica do livro de incorporar tanto a experiência dos estudantes e seu olhar crítico quanto a análise crítica de pesquisadores experientes. Com coragem suficiente para enxergar e descrever as novas iatrogenias geradas no interior do modelo, os desafios de formar cuidadores facilitadores e não dificultadores dos processos de (des) institucionalização.

Finalmente, na terceira parte do livro, os autores reafirmam o caráter avaliativo da pesquisa e o compromisso de todos na construção de convergências e consensos que resultem em reflexões avaliativas que possam subsidiar ajustes de rota e decisões para o enfrentamento dos desafios próprios às políticas públicas em construção. Há um esforço de síntese do trabalho investigativo das quatro áreas envolvidas - antropologia, arquitetura, saúde coletiva e psicanálise - que resulta na discussão do que envolve habitar uma casa protegida pelo campo do terapêutico, habitar uma casa, habitar uma grande cidade.

A dimensão do processo de pesquisa traduzido em livro nos impede de incluir neste espaço uma descrição pormenorizada da análise de dados e dos resultados do trabalho. Neste momento, remetemos o leitor ao próprio livro onde ele vai encontrar um conjunto de recomendações e proposições que possam ser fio condutor em seus próprios labirintos. São reflexões que nos levam a conceber lugares de moradia como uma construção sensível e orientada para as necessidades íntimas e sociais daqueles que têm sofrimentos psíquicos graves. Parece que a nós, cuidadores e pesquisadores de todas as áreas, resta-nos a aprendizagem da (des) institucionalização, o acompanhamento de muitas vidas construídas para sobreviver à crueldade da exclusão social e a luta política por cidades que nos comportem a todos. 